\title{
Efficacy of a Low Dose of Estrogen on Antioxidant Defenses and Heart Rate Variability
}

\author{
Cristina Campos, ${ }^{1}$ Karina Rabello Casali, ${ }^{2}$ Dhãniel Baraldi, ${ }^{1}$ \\ Adriana Conzatti, ${ }^{1}$ Alex Sander da Rosa Araújo, ${ }^{1}$ Neelam Khaper, ${ }^{3}$ Susana Llesuy, ${ }^{4}$ \\ Katya Rigatto, ${ }^{5}$ and Adriane Belló-Klein ${ }^{1}$ \\ ${ }^{1}$ Universidade Federal do Rio Grande do Sul, Sarmento Leite, 500 Bairro Farroupilha, 90050-170 Porto Alegre, RS, Brazil \\ ${ }^{2}$ Instituto de Cardiologia do Rio Grande do Sul, 90620-001 Porto Alegre, RS, Brazil \\ ${ }^{3}$ Medical Sciences Division, Northern Ontario School of Medicine, Lakehead University, Thunder Bay, ON, Canada P7B 5E1 \\ ${ }^{4}$ Universidad de Buenos Aires, C1053ABJ Buenos Aires, Argentina \\ ${ }^{5}$ Universidade Federal de Ciências da Saúde de Porto Alegre, 90050-170 Porto Alegre, RS, Brazil
}

Correspondence should be addressed to Adriane Belló-Klein; belklein@ufrgs.br

Received 20 November 2013; Revised 8 January 2014; Accepted 30 January 2014; Published 10 March 2014

Academic Editor: Dalton Valentim Vassallo

Copyright (C) 2014 Cristina Campos et al. This is an open access article distributed under the Creative Commons Attribution License, which permits unrestricted use, distribution, and reproduction in any medium, provided the original work is properly cited.

This study tested whether a low dose (40\% less than the pharmacological dose of $17-\beta$ estradiol) would be as effective as the pharmacological dose to improve cardiovascular parameters and decrease cardiac oxidative stress. Female Wistar rats $(n=$ 9/group) were divided in three groups: (1) ovariectomized (Ovx), (2) ovariectomized animals treated for 21 days with low dose (LE; $0.2 \mathrm{mg}$ ), and (3) high dose (HE; $0.5 \mathrm{mg}$ ) $17-\beta$ estradiol subcutaneously. Hemodynamic assessment and spectral analysis for evaluation of autonomic nervous system regulation were performed. Myocardial superoxide dismutase (SOD) and catalase (CAT) activities, redox ratio (GSH/GSSG), total radical-trapping antioxidant potential (TRAP), hydrogen peroxide, and superoxide anion concentrations were measured. HE and LE groups exhibited an improvement in hemodynamic function and heart rate variability. These changes were associated with an increase in the TRAP, GSH/GSSG, SOD, and CAT. A decrease in hydrogen peroxide and superoxide anion was also observed in the treated estrogen groups as compared to the Ovx group. Our results indicate that a low dose of estrogen is just as effective as a high dose into promoting cardiovascular function and reducing oxidative stress, thereby supporting the approach of using low dose of estrogen in clinical settings to minimize the risks associated with estrogen therapy.

\section{Introduction}

The risk of cardiovascular disease (CVD) increases dramatically in the postmenopausal women as compared to the premenopausal women. Estrogen helps to protect women against CVD during the childbearing years and, after menopause, the CVD can be prevented or at least reduced by estrogen therapy [1-3]. It has been demonstrated that estrogen therapy can reduce many risk factors, improving lipid profile and glucose metabolism [1].

The increased risk of CVD in menopause is also accompanied by oxidative stress, a condition when there is an increase in reactive oxygen species (ROS) levels which may cause oxidative damage to cells [4]. On the other hand, cells have mechanisms to protect from ROS mediated toxicity. Glutathione (GSH) is the major nonenzymatic antioxidant and participates in many cellular reactions of ROS scavenging. In such reactions, GSH is oxidized to form glutathione disulfide (GSSG). An increase in the redox ratio which is represented by GSH/GSSG is indicative of reduced oxidative stress [5]. An impairment in redox balance plays an important role in the reduced nitric oxide bioavailability which may ultimately affect the sympathovagal balance (SVB) [6, 7]. Moreover, some studies have reported a link between menopause and SVB impairment $[8,9]$ suggesting a role of estrogen in the autonomic nervous control of the cardiovascular system.

Power spectral analysis of heart rate variability (HRV) is a noninvasive method to assess SVB [10]. Alterations in HRV, 
which primarily reflect the tonic autonomic modulation, may have substantial clinical implications. Low HRV, which has been shown in postmenopausal women, is associated with an increased risk of CVD [11]. In addition, some studies indicate that menopausal women have a sympathovagal imbalance and that estrogen improves the SVB centrally and peripherally by decreasing sympathetic and increasing parasympathetic tone [12].

Estrogen therapy improves women's quality of life [13] and is widely used for controlling typical menopausal symptoms such as vaginal atrophy, hot flushes, osteoporosis, and sleep disturbances [14]. However, at standard pharmacological doses, several adverse effects, including higher risk of breast cancer, stroke, and venous thromboembolism, outweigh the benefits of estrogen therapy [15].

As cardiovascular diseases are highly prevalent after menopause [16] and estrogen is the most commonly used treatment to reduce menopause symptoms [13], the need to find a safer estrogen dose to control menopause related discomforts has been recommended. Indeed, studies evaluating different regimens of hormone therapy have demonstrated that a low dose of estrogen is associated with a significant decrease in mammographic density [17]. According to Mercuro et al. [18], low doses of estrogen are just as effective as conventional doses to improve the lipid profile and the endothelial function. Moreover, a low dose of estrogen has demonstrated to be effective for the alleviation of climacteric symptoms [19] and it has good tolerability associated with a low incidence of the most common side effects [20].

There have been no studies to date that have tested the effects of low dose of estrogen on oxidative stress and its association with the cardiac autonomic control in ovariectomized rats. Thus, the aim of this study was to test whether the treatment with a low dose of $17-\beta$ estradiol to ovariectomized rats could be as effective as a pharmacological dose to reduce the cardiac oxidative stress and improve the SVB.

\section{Methods}

2.1. Drugs and Reagents. Ketamine hydrochloride was purchased from König Lab S.A., SP, Brazil, and xylazine, from Virbac do Brazil I.P., SP, Brazil. 17- $\beta$ estradiol and all other drugs/reagents were purchased from Sigma Chemical Co., St. Louis.

2.2. Animals and Groups. In total, 27 female Wistar rats (body weight 200-230 g) from the animal care of the Federal University of Rio Grande do Sul, Brazil, were kept at $20-22^{\circ} \mathrm{C}$ in a $12: 12 \mathrm{~h}$ dark/light cycle. They were subjected to bilateral ovariectomy under ketamine hydrochloride $(80 \mathrm{mg} / \mathrm{kg}$ i.p.) and xylazine $(16 \mathrm{mg} / \mathrm{kg}$ i.p.) anesthesia. After one week following ovariectomy, each ovariectomized animal received subcutaneously (under ketamine and xylazine anesthesia) silastic capsules either filled with $17-\beta$ estradiol diluted in sunflower oil (treated groups) or only sunflower oil as a vehicle (ovariectomized control group). Rats were divided into three experimental groups ( $n=9$, per group): (1) ovariectomized (Ovx) receiving only sunflower oil, (2) animals treated with
$40 \%$ of the pharmacological (LE; $0.2 \mathrm{mg} /$ pellet for 21 days) dose of estradiol, and (3) animals treated with a pharmacological (HE; $0.5 \mathrm{mg} /$ pellet for 21 days) dose of estradiol [21]. All animals had access to water and regular rodent chow ad libitum. All procedures were approved by the Institutional Animal Care Ethics Committee and the experiments were conducted in accordance with the Guide for the Care and Use of Laboratory Animals (US Department of Health and Human Services, NIH publication number 86-23).

2.3. Hemodynamic Measurements. Under anesthesia (ketamine $80 \mathrm{mg} / \mathrm{kg}$, i.p.; xylazine $16 \mathrm{mg} / \mathrm{kg}$, i.p.), the left carotid artery was cannulated with a PE 50 catheter connected to a strain gauge transducer (Narco Biosystem Pulse Transducer RP-155, Houston, TX, USA) linked to a pressure amplifier (HP 8805C, Hewlett Packard). Pressure readings were recorded on a microcomputer equipped with an analogto-digital conversion board (WinDaq, $2 \mathrm{kHz}$ sampling frequency; DataQ Instruments, Inc., Akron, OH). The catheter was advanced into the left ventricle (LV) to record the left ventricular systolic pressure (LVSP, $\mathrm{mmHg}$ ), the left ventricular end-diastolic pressure (LVEDP, $\mathrm{mmHg}),+d P / d t(\mathrm{mmHg} / \mathrm{s})$, $-d P / d t(\mathrm{mmHg} / \mathrm{s})$, and heart rate (HR). After hemodynamic measurements, animals were sacrificed by decapitation for heart and blood collection.

2.4. Autonomic Evaluation. After detecting the pulse intervals, the heart rate was automatically calculated on a beatto-beat basis as the time interval between two consecutive systolic peaks or pulse interval (PI). All detection was carefully checked to avoid erroneous or missed beats. Sequences of 150-160 beats were randomly chosen and if there was an inconsistent pattern, it was discarded and a new random selection was performed. Frequency domain analysis of HRV was performed with an autoregressive algorithm [22] on the PI interval sequences (tachograms) and on respective systolic sequences (cystograms). The power spectral density was calculated for each time series. In this study, two spectral components were considered: low frequency (LF), from 0.10 to $1.00 \mathrm{~Hz}$ and high frequency (HF), from 1.00 to $5.00 \mathrm{~Hz}$. The spectral components were expressed in absolute (abs) and normalized units (nu). Normalization consisted of dividing the power of a given spectral component by the total power, then multiplying the ratio by 100 [23]. All recordings were performed in a sound attenuated room. The ratio of LF/HF, as an index of SVB, was also calculated.

2.5. Plasma Hormone Concentration. Plasma estradiol was measured by electrochemiluminescence (Roche Diagnostics) at the Weinmann Clinical Analysis Laboratory. Briefly, this test employs the principle of competitive assay using a polyclonal antibody against the $17-\beta$ estradiol.

2.6. Hydrogen Peroxide Concentration. The assay was based on the horseradish peroxidase- (HRPO-) mediated oxidation of phenol red by $\mathrm{H}_{2} \mathrm{O}_{2}$, leading to the formation of a compound measureable at $610 \mathrm{~nm}$. Heart slices were incubated for $30 \mathrm{~min}$ at $37^{\circ} \mathrm{C}$ in $10 \mathrm{mmol} / \mathrm{L}$ phosphate buffer consisting of 
$140 \mathrm{mmol} / \mathrm{L} \mathrm{NaCl}$ and $5 \mathrm{mmol} / \mathrm{L}$ dextrose. The supernatants were transferred to tubes with $0.28 \mathrm{mmol} / \mathrm{L}$ phenol red and 8.5 U/mL HRPO. After $5 \mathrm{~min}$ incubation, $1 \mathrm{~mol} / \mathrm{L} \mathrm{NaOH}$ was added and it was read at $610 \mathrm{~nm}$. The results were expressed in $\mathrm{nmol} \mathrm{H}_{2} \mathrm{O}_{2} / \mathrm{g}$ tissue [24].

\subsection{Determination of Superoxide Anion Concentration.} Superoxide anion concentration was determined in heart mitochondrial samples isolated by centrifugations. It was based on the spectrophotometric measurement of the epinephrine oxidation reaction in which superoxide anion is a reactant, leading to the formation of a compound measureable at $480 \mathrm{~nm}$. The results were expressed in $\mathrm{mmol} / \mathrm{mg}$ protein [25].

2.8. Preparation of Heart Homogenates for Analysis of Antioxidants. Hearts were homogenized in an ultra-Turrax blender using $1 \mathrm{~g}$ of tissue for $5 \mathrm{~mL}$ of $150 \mathrm{mmol} / \mathrm{L}$ potassium chloride added to $20 \mathrm{mmol} / \mathrm{L}$ phosphate buffer, $\mathrm{pH} 7.4$. The homogenates were centrifuged at $1000 \mathrm{~g}$ for $20 \mathrm{~min}$ at $-2^{\circ} \mathrm{C}$ as described elsewhere [26].

2.9. TRAP. Total antioxidant capacity (TRAP) was measured by chemiluminescence using 2,2'-azo-bis(2-amidinopropane) (ABAP, a source of alkyl peroxyl free radicals) and luminol. A mixture consisting of $20 \mathrm{mmol} / \mathrm{L} \mathrm{ABAP}$, $40 \mu \mathrm{mol} / \mathrm{L}$ luminol, and $50 \mathrm{mmol} / \mathrm{L}$ phosphate buffer $(\mathrm{pH}$ 7.4) was incubated to achieve a steady-state luminescence from the free radical-mediated luminol oxidation. A calibration curve was obtained by using different concentrations (between 0.2 and $1 \mu \mathrm{mol} / \mathrm{L}$ ) of Trolox (hydrosoluble form of vitamin E). Luminescence was measured in a liquid scintillation counter using the out-of-coincidence mode and the results were expressed in units of Trolox/mg protein [27].

\subsection{Determination of Total and Oxidized Glutathione Con-} centration. To determine oxidized (GSSG) and total glutathione concentration, tissue was homogenized in $2 \mathrm{~mol} / \mathrm{L}$ perchloric acid and centrifuged at $1000 \mathrm{~g}$ for $10 \mathrm{~min}$ and $2 \mathrm{~mol} / \mathrm{L}$ potassium hydroxide was added to the supernatant. The reaction medium contained $100 \mathrm{mmol} / \mathrm{L}$ phosphate buffer ( $\mathrm{pH} 7.2$ ), $2 \mathrm{mmol} / \mathrm{L} \mathrm{NADPH}, 0.2 \mathrm{U} / \mathrm{mL}$ glutathione reductase, and $70 \mu \mathrm{mol} / \mathrm{L} 5,5^{\prime}$ dithiobis (2-nitrobenzoic acid). To determine oxidized glutathione, the supernatant was neutralized with $2 \mathrm{~mol} / \mathrm{L}$ potassium hydroxide and inhibited by the addition of $5 \mu \mathrm{mol} / \mathrm{L}$ N-ethylmaleimide and absorbance was read at $420 \mathrm{~nm}$ [28]. Reduced glutathione (GSH) values were determined from the total and GSSG concentration. The redox status was represented by the GSH/GSSG ratio.

2.11. Determination of Antioxidant Enzyme Activities. Superoxide dismutase activity was expressed as units per milligram of protein and is based on the inhibition of superoxide radical reaction with pyrogallol [29]. Catalase activity was determined in heart homogenates by following the decrease in absorption of hydrogen peroxide. It was expressed as $\mathrm{pmol} / \mathrm{mg}$ protein [30]. Protein was measured in heart
TABLE 1: Morphometrics data.

\begin{tabular}{lccc}
\hline & Ovx $(N=9)$ & LE $(N=9)$ & HE $(N=9)$ \\
\hline Uterine weight $(\mathrm{g})$ & $0.15 \pm 0.01$ & $0.63 \pm 0.02^{*}$ & $0.89 \pm 0.13^{* \dagger}$ \\
Body weight $(\mathrm{g})$ & $234 \pm 11$ & $209 \pm 9^{*}$ & $210 \pm 7^{*}$ \\
\hline
\end{tabular}

Data are mean \pm SD. Ovx: ovariectomized group; HE: high dose estrogentreated group; LE: low dose estrogen-treated group. ${ }^{*} P<0.05$ versus Ovx; ${ }^{\dagger} P<0.05$ versus $L E$.

TABLE 2: Left ventricular hemodynamic parameters.

\begin{tabular}{lccc}
\hline & Ovx $(N=5)$ & LE $(N=5)$ & HE $(N=5)$ \\
\hline LVEDP $(\mathrm{mmHg})$ & $12.17 \pm 4.54$ & $5.10 \pm 1.98^{*}$ & $7.95 \pm 2.21^{*}$ \\
LVSP $(\mathrm{mmHg})$ & $101.71 \pm 12.78$ & $120.91 \pm 20.71$ & $110.40 \pm 7.51$ \\
$\mathrm{HR}(\mathrm{bpm})$ & $212 \pm 12.78$ & $221 \pm 22.59$ & $183.81 \pm 20.83$ \\
$+\mathrm{dP} / \mathrm{dt}(\mathrm{mmHg} / \mathrm{s})$ & $5809 \pm 924$ & $6435 \pm 549$ & $5505 \pm 450$ \\
$-\mathrm{dP} / \mathrm{dt}(\mathrm{mmHg} / \mathrm{s})$ & $-3946 \pm 786$ & $-5262 \pm 890$ & $-4098 \pm 251$ \\
\hline
\end{tabular}

Data are mean \pm SD. Ovx: ovariectomized group; HE: high dose estrogentreated group; LE: low dose estrogen-treated group. ${ }^{*} P<0.05$ versus Ovx.

homogenates, using bovine serum albumin as described by Lowry et al. [31].

2.12. Statistical Analysis. Data are shown as mean \pm standard deviation. Statistical analyses were performed using one-way ANOVA followed by Student Newman-Keuls post hoc test. The Pearson correlation was used to assess the association among variables. $P<0.05$ was considered significant.

\section{Results}

3.1. Ovariectomy and Estradiol Therapy. As expected, the ovariectomy decreased plasma estrogen concentration and $17-\beta$ estradiol treatment increased its concentration $(\mathrm{LE}=587$ $\pm 19 \mathrm{pg} / \mathrm{L}, \mathrm{HE}=1813 \pm 37 \mathrm{pg} / \mathrm{L}$ versus $\mathrm{Ovx}=58 \pm 6 \mathrm{pg} / \mathrm{L})$. This result is in consonance with Paigel et al. [32], who observed serum estrogen levels in ovariectomized rats similar to those observed by us. Moreover, in ovary-intact animals, Paigel et al. [32] found estrogen serum concentration of about $120 \mathrm{pg} / \mathrm{L}$. The $17-\beta$ estradiol treatment also significantly $(P<$ 0.001 ) decreased the body weight and increased the uterine weight (Table 1), confirming the effectiveness of hormonal treatment.

3.2. Hemodynamic Parameters. The LVEDP, which is a diastolic function, was significantly $(P<0.05)$ decreased in LE (by 60\%) and HE (by 35\%) groups when compared to Ovx animals. Moreover, no changes were found in $+d P / d t$, a cardiac contractility index, and $-d P / d t$, a cardiac relaxation index, LVSP, and HR, among any of the groups (Table 2).

3.3. Autonomic Evaluations. Hfabs, which represents the parasympathetic drive, and HRV were significantly higher $(P<0.05)$ in both the HE and LE groups as compared to the Ovx group. LFabs, LFnu, HFnu, and LF/HF ratio did not show any statistically significant differences with estrogen treatment (Table 3). 
TABLE 3: Power spectral analysis.

\begin{tabular}{lccc}
\hline & Ovx $(N=5)$ & LE $(N=5)$ & HE $(N=5)$ \\
\hline HRV $\left(\mathrm{ms}^{2}\right)$ & $14.34 \pm 3.56$ & $39.98 \pm 11.00^{*}$ & $69.62 \pm 27.32^{*}$ \\
LFabs $\left(\mathrm{ms}^{2}\right)$ & $2.49 \pm 1.53$ & $5.03 \pm 1.89$ & $8.09 \pm 7.04$ \\
HFabs $\left(\mathrm{ms}^{2}\right)$ & $9.78 \pm 2.84$ & $28.04 \pm 9.718^{*}$ & $53.35 \pm 29.96^{*}$ \\
LFnu & $20.22 \pm 5.20$ & $16.67 \pm 5.12$ & $11.05 \pm 3.03$ \\
HFnu & $79.77 \pm 5.14$ & $83.32 \pm 5.10$ & $88.95 \pm 15.74$ \\
LF/HF & $0.25 \pm 0.07$ & $0.2 \pm 0.07$ & $0.12 \pm 0.08$ \\
\hline
\end{tabular}

Data are mean \pm SD. Ovx: ovariectomized group; HE: high dose estrogentreated group; LE: low dose estrogen-treated group; HRV: heart rate variability; LFabs: absolute low frequency; HFabs: absolute high frequency; LFnu: normalized low frequency; HFnu: normalized high frequency. ${ }^{*} P<0.05$ versus Ovx.

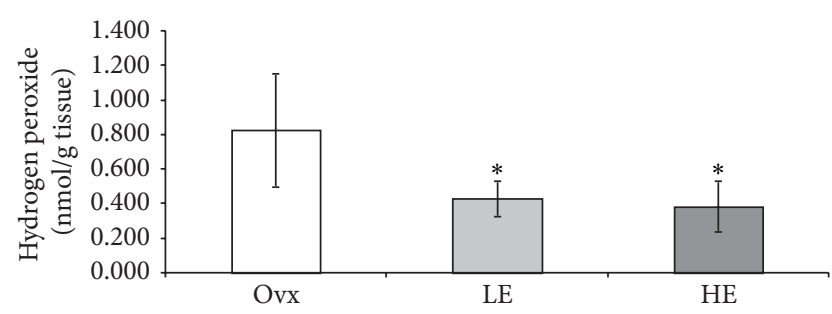

(a)

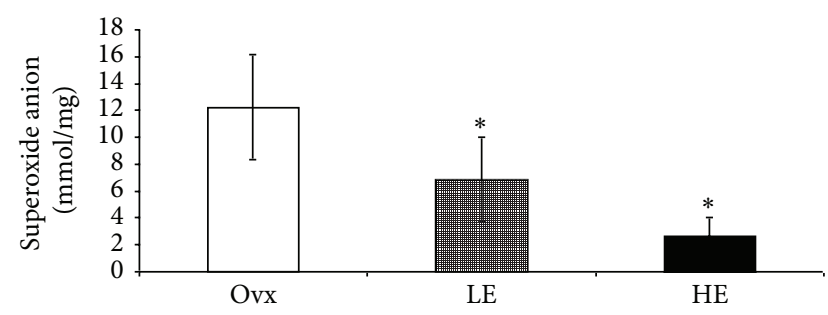

(b)

FIgURE 1: (a) Hydrogen peroxide concentration in myocardium (in $\mathrm{nmol} / \mathrm{g}$ tissue) and (b) superoxide anion concentration in myocardium (in $\mathrm{mmol} / \mathrm{mg}$ protein). Data are mean $\pm \mathrm{SD} . N=9$ per group. Ovariectomized group = Ovx; ovariectomized group treated for 21 days with low dose of estrogen = LE; ovariectomized group treated for 21 days with high dose of estrogen $=$ HE. ${ }^{*} P<0.05$ versus Ovx.

3.4. Reactive Oxygen Species Concentrations. Cardiac $\mathrm{H}_{2} \mathrm{O}_{2}$ concentration (in $\mathrm{nmol} / \mathrm{g}$ tissue) was significantly decreased $(P<0.05)$ in estrogen groups as compared to the Ovx group $(\mathrm{LE}=0.43 \pm 0.10 ; \mathrm{HE}=0.38 \pm 0.14$ versus $\mathrm{Ovx}=$ $0.83 \pm 0.32$ (Figure 1(a)). Similarly, the cardiac superoxide anion concentration ( $\mathrm{mmol} / \mathrm{mg}$ protein) was significantly $(P<0.05)$ decreased in the treated groups ( $\mathrm{LE}=6.87 \pm 3.13$; $\mathrm{HE}=2.65 \pm 1.37)$ as compared to the Ovx group (Ovx = $12.22 \pm 3.90$ ) (Figure 1(b)).

3.5. TRAP, Glutathione Concentration, and the Redox Ratio. Total antioxidant capacity was significantly higher in estrogen treated groups as compared to the Ovx group. Moreover, a strong positive correlation between TRAP and HRV $(r=$ 0.8922; $P<0.01)$ was also observed. GSSG levels decreased in the HE group as compared to Ovx group. The redox

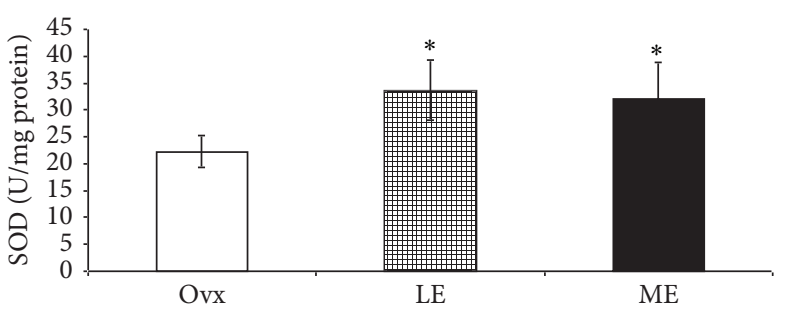

(a)

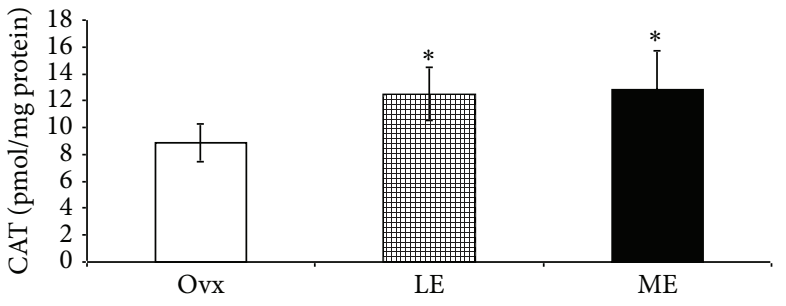

(b)

FIGURE 2: (a) Superoxide dismutase activity (U/mg protein) and (b) catalase activity (pmol/mg protein). Data are mean $\pm \mathrm{SD} . N=9$ per group. Ovariectomized group $=\mathrm{Ovx}$; ovariectomized group treated for 21 days with low dose of estrogen = LE; ovariectomized group treated for 21 days with high dose of estrogen $=\mathrm{HE} .{ }^{*} P<0.05$ versus Ovx.

(GSH/GSSG) ratio, which is an index of oxidative stress, and GSH were significantly $(P<0.05)$ higher in both the estrogen treated groups when compared to the Ovx group (Table 4).

3.6. Antioxidant Enzyme Activities. SOD and CAT activities were significantly higher in estrogen treated groups (SOD in $\mathrm{U} / \mathrm{mg}$ protein: $\mathrm{LE}=33.65 \pm 5.54 ; \mathrm{HE}=32.10 \pm 6.80 ; \mathrm{CAT}$ in $\mathrm{pmol} / \mathrm{mg}$ protein: $12.5 \pm 2.0 ; 12.8 \pm 2.9)$ as compared to the Ovx group (SOD: $22.24 \pm 3.00$; CAT: $8.9 \pm 1.4$ ), and there was no difference between HE and LE groups (Figures 2(a) and 2(b)).

\section{Discussion}

The present study showed for the first time that a low dose of estrogen is just as effective as a high dose to improve the antioxidant reserve and reduces cardiac oxidative stress. This was associated with a lower LVEDP and higher HRV, which signifies reduced cardiovascular risk.

In this study, we reported a significant decrease in LVEDP in both estrogen-treated groups. This result is in agreement with a study from Bhuiyan et al. [33] who demonstrated similar values of LVEDP in ovariectomized rats. Moreover, we did not observe significant differences in $+d P / d t$, an index of myocardial contractility, or $-d P / d t$, an index of myocardial relaxation, neither in LVSP and HR. Furthermore, our study also is in consonance with Nekooeian and Pang [34] who documented a decrease in LVEDP in rats treated with a pharmacological dose of estrogen. This result suggests a reduction in afterload with maintained systolic function. Indeed, in another study we observed that estrogen therapy induces an increase in aortic nitric oxide bioavailability, 
TABle 4: Myocardial nonenzymatic antioxidant defenses.

\begin{tabular}{lccc}
\hline & $\operatorname{Ovx}(N=9)$ & LE $(N=9)$ & HE $(N=9)$ \\
\hline TRAP (units of Trolox/mg protein) & $25.50 \pm 7.96$ & $57.60 \pm 24.13^{*}$ & $53.55 \pm 16.15^{*}$ \\
Total GSH (nmol/mg protein) & $0.18 \pm 0.08$ & $0.32 \pm 0.06^{*}$ & $0.28 \pm 0.14^{*}$ \\
GSSG (nmol/mg protein) & $0.026 \pm 0.008$ & $0.022 \pm 0.005$ & $0.014 \pm 0.005^{*}$ \\
GSH/GSSG & $5.98 \pm 2.45$ & $13.57 \pm 2.23^{*}$ & $19.55 \pm 9.03^{*}$ \\
\hline
\end{tabular}

Data are mean \pm SD. Ovx: ovariectomized group; HE: high dose estrogen-treated group; LE: low dose estrogen-treated group. ${ }^{*} P<0.05$ versus Ovx.

resulting in an increase in vasodilation and blood pressure reduction [7]. Estradiol has been reported to play a role in mediating a reduction in blood pressure in hypertensive female animal models $[7,35,36]$. Moreover, since nitric oxide is reported to increase diastolic distensibility [37], estrogen treatment could prevent the increase of LVEDP by increasing nitric oxide synthase activity in the heart as reported by others [38].

We did not find changes in LFa, LFnu, HFnu, and LF/HF ratio in the two treated groups. These results are consistent with Schuchert et al. [39] who have also demonstrated no changes in these parameters after estrogen treatment. On the other hand, HFabs, an important index of cardiac parasympathetic modulation [23], was significantly improved after estrogen treatment representing reduced cardiovascular risk [40]. HRV was also increased in the estrogen treated groups. This result is in agreement with Liu et al. [41] who have reported that estrogen therapy is able to improve cardiac autonomic control. Although no changes were found in HR, our results demonstrated that there was a significant increase in HRV after estrogen treatment. This result highlights the effectiveness of estrogen, even in a low dose, to increase HRV and potentially lower the risk factors for cardiovascular complications [42]. More importantly, in our current study, we also found a positive correlation between HRV and TRAP $(r=0.8922 ; P<0.01)$, suggesting that an increase in the antioxidant capacity might contribute to the improvement in cardiac autonomic control. This association supports the hypothesis that estrogen administration increases nonenzymatic antioxidants, which improves cardiac autonomic control and reduces oxidative stress. According to Semen et al. [43], a decrease in oxidative stress results in an improved HRV. It has also been reported that estrogen therapy leads to an increase in total serum antioxidant capacity resulting in an improvement in the antioxidant status in women [44]. Accordingly, in the treated groups, we have observed an increase in TRAP that represents an index of nonenzymatic antioxidants, especially the hydrosoluble ones. One possible explanation to this preservation in the nonenzymatic antioxidants could be the enhanced antioxidant enzyme activity. In fact, SOD and CAT activities were significantly higher after estrogen treatment. These results are in agreement with others who have reported that estradiol has antioxidant properties whereby it increases CAT [45] and SOD activities and decreases NADPH oxidase enzyme activity and superoxide production [7, 45-47]. In the present study a significant decrease in cardiac concentrations of superoxide anion and hydrogen peroxide in animals treated with estrogen was also documented. These results are in consonance with a study of
Lam et al. [48] who demonstrated a significant decrease in superoxide anion production in aortas from ovariectomized rats treated with estrogen. According to our results, the low dose was also able to decrease these ROS concentrations. Additionally, it is widely recognized that estrogen exhibits protective antioxidant effects through the phenolic hydroxyl group of 17- $\beta$ estradiol that can act as a ROS scavenger [49]. Our findings do suggest that estrogen, even in a low dose, is able to improve the antioxidant defenses and decrease ROS concentrations.

Indeed, GSH/GSSG ratio was significantly increased and GSSG was decreased in our treated groups. These results indicate that there was a reduction in oxidative stress after estrogen treatment. Our data are in agreement with Baeza et al. [50], who also demonstrated that estrogen in a conventional dose was able to decrease oxidative stress in liver, heart, and kidney from ovariectomized rats.

This scenario, where antioxidants are increased and ROS concentration is decreased, contributes to a more favorable redox balance.

\section{Conclusion}

In conclusion, based on our results, estrogen therapy, even in a low dose, reduced cardiac ROS concentration and increased enzymatic and nonenzymatic antioxidants in ovariectomized rats. This was reflected in improved left ventricle function and cardiac autonomic control. Once these cardioprotective effects were similar in low and high dose of estrogen, it is reasonable to recommend low doses in clinical settings to avoid undesirable side effects associated with the high dose.

\section{Conflict of Interests}

The authors declare that there is no conflict of interests that could be perceived as prejudicing the impartiality of the research reported.

\section{Acknowledgment}

The authors would like to thank the Weinmann Clinical Analysis Laboratory for performing the hormone measurements.

\section{References}

[1] E. Murphy, "Estrogen signaling and cardiovascular disease," Circulation Research, vol. 109, no. 6, pp. 687-696, 2011. 
[2] J. Hsia, R. D. Langer, J. E. Manson et al., "Conjugated equine estrogens and coronary heart disease: the women's health initiative," Archives of Internal Medicine, vol. 166, no. 3, pp. 357365, 2006.

[3] J. E. Rossouw, R. L. Prentice, J. E. Manson et al., "Postmenopausal hormone therapy and risk of cardiovascular disease by age and years since menopause," Journal of the American Medical Association, vol. 297, no. 13, pp. 1465-1477, 2007.

[4] C. Vassalle, A. Mercuri, and S. Maffei, "Oxidative status and cardiovascular risk in women: keeping pink at heart," World Journal of Cardiology, vol. 1, pp. 26-30, 2009.

[5] G. Wu, Y. Z. Fang, S. Yang, J. R. Lupton, and N. D. Turner, "Glutathione metabolism and its implications for health," Journal of Nutrition, vol. 134, no. 3, pp. 489-492, 2004.

[6] B. Xue, M. Singh, F. Guo, M. Hay, and A. K. Johnson, "Protective actions of estrogen on angiotensin II-induced hypertension: role of central nitric oxide," The American Journal of Physiology-Heart and Circulatory Physiology, vol. 297, no. 5, pp. H1638-H1646, 2009.

[7] C. Campos, C. L. Sartorio, K. R. Casali et al., "Low dose estrogen is as effective as high dose treatment in rats with postmenopausal hypertension," Journal of Cardiovascular Pharmacology, vol. 63, no. 2, pp. 144-151, 2014.

[8] S. S. Moodithaya and S. T. Avadhany, "Comparison of cardiac autonomic activity between pre and post menopausal women using heart rate variability," Indian Journal of Physiology and Pharmacology, vol. 53, no. 3, pp. 227-234, 2009.

[9] D. Kaya, S. Cevrioglu, E. Onrat, I. V. Fenkci, and M. Yilmazer, "Single dose nasal 17beta-estradiol administration reduces sympathovagal balance to the heart in postmenopausal women," Journal of Obstetrics and Gynaecology Research, vol. 29, no. 6, pp. 406-411, 2003.

[10] J. S. Petrofsky, E. Lohman, and T. Lohman, "A device to evaluate motor and autonomic impairment," Medical Engineering and Physics, vol. 31, no. 6, pp. 705-712, 2009.

[11] G. Mercuro, A. Podda, L. Pitzalis et al., "Evidence of a role of endogenous estrogen in the modulation of autonomic nervous system," The American Journal of Cardiology, vol. 85, no. 6, pp. 787-789, 2000.

[12] P. M. McCabe, S. W. Porges, and C. S. Carter, "Heart period variability during estrogen exposure and withdrawal in female rats," Physiology and Behavior, vol. 26, no. 3, pp. 535-538, 1981.

[13] A. Yildirir, "Postmenopausal hormone replacement therapy and cardiovascular system," Turk Kardiyoloji Dernegi Arsivi, vol. 38, supplement 1, pp. 32-40, 2010.

[14] S. Rozenberg, J. Vandromme, and C. Antoine, "Reactualisation of hormonal treatment at the menopause in 2011," Revue Medicale de Bruxelles, vol. 32, no. 4, pp. 239-242, 2011.

[15] H. N. Hodis and W. J. Mack, "Postmenopausal hormone therapy in clinical perspective," Menopause, vol. 14, no. 5, pp. 944-957, 2007.

[16] K. A. Matthews, E. Meilahn, L. H. Kuller, S. F. Kelsey, A. W. Caggiula, and R. R. Wing, "Menopause and risk factors for coronary heart disease," The New England Journal of Medicine, vol. 321, no. 10, pp. 641-646, 1989.

[17] P. H. Wang, H. C. Horng, M. H. Cheng, H. T. Chao, and K. C. Chao, "Standard and low-dose hormone therapy for postmenopausal women-focus on the breast," Taiwanese Journal of Obstetrics and Gynecology, vol. 46, no. 2, pp. 127-134, 2007.

[18] G. Mercuro, C. Vitale, M. Fini, S. Zoncu, F. Leonardo, and G. M. C. Rosano, "Lipid profiles and endothelial function with low-dose hormone replacement therapy in postmenopausal women at risk for coronary artery disease: a randomized trial," International Journal of Cardiology, vol. 89, no. 2-3, pp. 257-265, 2003.

[19] R. Schürmann, T. Holler, and N. Benda, "Estradiol and drospirenone for climacteric symptoms in postmenopausal women: a double-blind, randomized, placebo-controlled study of the safety and efficacy of three dose regimens," Climacteric, vol. 7, no. 2, pp. 189-196, 2004.

[20] P. H. van de Weijer, L. A. Mattsson, and O. Ylikorkala, "Benefits and risks of long-term low-dose oral continuous combined hormone therapy," Maturitas, vol. 56, no. 3, pp. 231-248, 2007.

[21] S. E. Campbell and M. A. Febbraio, "Effect of the ovarian hormones on GLUT4 expression and contraction-stimulated glucose uptake," The American Journal of PhysiologyEndocrinology and Metabolism, vol. 282, no. 5, pp. E1139-E1146, 2002.

[22] A. Malliani, M. Pagani, F. Lombardi, and S. Cerutti, "Cardiovascular neural regulation explored in the frequency domain," Circulation, vol. 84, no. 2, pp. 482-492, 1991.

[23] N. Montano, T. G. Ruscone, A. Porta, F. Lombardi, M. Pagani, and A. Malliani, "Power spectrum analysis of heart rate variability to assess the changes in sympathovagal balance during graded orthostatic tilt," Circulation, vol. 90, no. 4 I, pp. 18261831, 1994.

[24] E. Pick and Y. Keisari, "A simple colorimetric method for the measurement of hydrogen peroxide produced by cells in culture," Journal of Immunological Methods, vol. 38, no. 1-2, pp. 161170, 1980.

[25] A. Boveris, "Determination of the production of superoxide radicals and hydrogen peroxide in mitochondria," Methods in Enzymology, vol. 105, pp. 429-435, 1984.

[26] S. F. Llesuy, J. Milei, and H. Molina, "Comparison of lipid peroxidation and myocardial damage induced by adriamycin and $4^{\prime}$-epiadriamycin in mice," Tumori, vol. 71, no. 3, pp. 241-249, 1985.

[27] P. Evelson, M. Travacio, M. Repetto, J. Escobar, S. Llesuy, and E. A. Lissi, "Evaluation of total reactive antioxidant potential (TRAP) of tissue homogenates and their cytosols," Archives of Biochemistry and Biophysics, vol. 388, no. 2, pp. 261-266, 2001.

[28] T. P. Akerboom and H. Sies, "Assay of glutathione, glutathione disulfide, and glutathione mixed disulfides in biological samples," Methods in Enzymology, vol. 77, no. C, pp. 373-382, 1981.

[29] S. L. Marklund, "Superoxide dismutase isoenzymes in tissues and plasma from New Zealand black mice, nude mice and normal BALB/c mice," Mutation Research, vol. 148, no. 1-2, pp. 129-134, 1985.

[30] H. Aebi, "Catalase in vitro," Methods in Enzymology, vol. 105, no. C, pp. 121-126, 1984.

[31] O. H. Lowry, N. J. Rosebrough, A. L. Farr, and R. J. Randall, "Protein measurement with the Folin phenol reagent," The Journal of biological chemistry, vol. 193, no. 1, pp. 265-275, 1951.

[32] A. S. Paigel, R. F. Ribeiro Junior, A. A. Fernandes, G. P. Targueta, D. V. Vassallo, and I. Stefanon, "Myocardial contractility is preserved early but reduced late after ovariectomy in young female rats," Reproductive Biology and Endocrinology, vol. 9, article 54, 2011.

[33] M. S. Bhuiyan, N. Shioda, and K. Fukunaga, "Ovariectomy augments pressure overload-induced hypertrophy associated 
with changes in Akt and nitric oxide synthase signaling pathways in female rats," The American Journal of PhysiologyEndocrinology and Metabolism, vol. 293, no. 6, pp. E1606-E1614, 2007.

[34] A. A. Nekooeian and C. C. Y. Pang, "Estrogen restores role of basal nitric oxide in control of vascular tone in rats with chronic heart failure," The American Journal of Physiology-Heart and Circulatory Physiology, vol. 274, no. 6, pp. H2094-H2099, 1998.

[35] Z. Wu, C. Maric, D. M. Roesch, W. Zheng, J. G. Verbalis, and K. Sandberg, "Estrogen regulates adrenal angiotensin AT1 receptors by modulating AT1 receptor translation," Endocrinology, vol. 144, no. 7, pp. 3251-3261, 2003.

[36] C. Hinojosa-Laborde, D. L. Lange, and J. R. Haywood, "Role of female sex hormones in the development and reversal of Dahl hypertension," Hypertension, vol. 35, no. 1, pp. 484-489, 2000.

[37] B. D. Prendergast, V. F. Sagach, and A. M. Shah, "Basal release of nitric oxide augments the Frank-Starling response in the isolated heart," Circulation, vol. 96, no. 4, pp. 1320-1329, 1997.

[38] S. Nuedling, S. Kahlert, K. Loebbert et al., "17 $\beta$-estradiol stimulates expression of endothelial and inducible NO synthase in rat myocardium in-vitro and in-vivo," Cardiovascular Research, vol. 43 , no. 3, pp. 666-674, 1999.

[39] A. Schuchert, M. Liebau, G. Behrens, A. O. Mueck, and T. Meinertz, "Are the acute effects of transdermal estradiol in postmenopausal women with coronary artery disease related to changes of the autonomic tone?" Zeitschrift fur Kardiologie, vol. 91, no. 2, pp. 156-160, 2002.

[40] F. M. Abboud, S. C. Harwani, and M. W. Chapleau, "Autonomic neural regulation of the immune system: implications for hypertension and cardiovascular disease," Hypertension, vol. 59, no. 4, pp. 755-762, 2012.

[41] C. C. Liu, T. B. J. Kuo, and C. C. H. Yang, "Effects of estrogen on gender-related autonomic differences in humans," The American Journal of Physiology-Heart and Circulatory Physiology, vol. 285, no. 5, pp. H2188-H2193, 2003.

[42] M. W. Gillman, W. B. Kannel, A. Belanger, and R. B. D’Agostino, "Influence of heart rate on mortality among persons with hypertension: the Framingham Study," The American Heart Journal, vol. 125, no. 4, pp. 1148-1154, 1993.

[43] K. O. Semen, O. P. Yelisyeyeva, D. V. Kaminskyy et al., "Interval hypoxic training in complex treatment of Helicobacter pyloriassociated peptic ulcer disease," Acta Biochimica Polonica, vol. 57, no. 2, pp. 199-208, 2010.

[44] M. Darabi, M. Ani, A. Movahedian, E. Zarean, M. Panjehpour, and M. Rabbani, "Effect of hormone replacement therapy on total serum anti-oxidant potential and oxidized ldl/ß2-glycoprotein i complexes in postmenopausal women," Endocrine Journal, vol. 57, no. 12, pp. 1029-1034, 2010.

[45] M. A. Gómez-Zubeldia, S. Corrales, J. Arbués, A. G. Nogales, and J. C. Millán, "Influence of estradiol and gestagens on oxidative stress in the rat uterus," Gynecologic Oncology, vol. 86, no. 3, pp. 250-258, 2002.

[46] H. Ji, W. Zheng, S. Menini et al., "Female protection in progressive renal disease is associated with estradiol attenuation of superoxide production," Gender Medicine, vol. 4, no. 1, pp. 56-71, 2007.

[47] A. A. Miller, G. R. Drummond, A. E. Mast, H. H. H. W. Schmidt, and C. G. Sobey, "Effect of gender on NADPH-oxidase activity, expression, and function in the cerebral circulation: role of estrogen," Stroke, vol. 38, no. 7, pp. 2142-2149, 2007.

[48] K. K. Lam, Y. M. Lee, G. Hsiao, S. Y. Chen, and M. H. Yen, "Estrogen therapy replenishes vascular tetrahydrobiopterin and reduces oxidative stress in ovariectomized rats," Menopause, vol. 13, no. 2, pp. 294-302, 2006.

[49] C. Behl, T. Skutella, F. Lezoualc'h et al., "Neuroprotection against oxidative stress by estrogens: structure-activity relationship," Molecular Pharmacology, vol. 51, no. 4, pp. 535-541, 1997.

[50] I. Baeza, J. Fdez-Tresguerres, C. Ariznavarreta, and M. De La Fuente, "Effects of growth hormone, melatonin, oestrogens and phytoestrogens on the oxidized glutathione (GSSG)/reduced glutathione (GSH) ratio and lipid peroxidation in aged ovariectomized rats," Biogerontology, vol. 11, no. 6, pp. 687-701, 2010. 


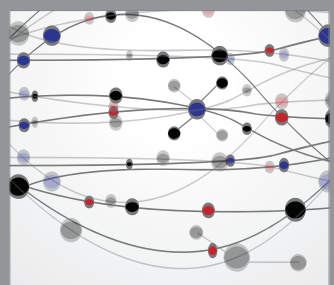

The Scientific World Journal
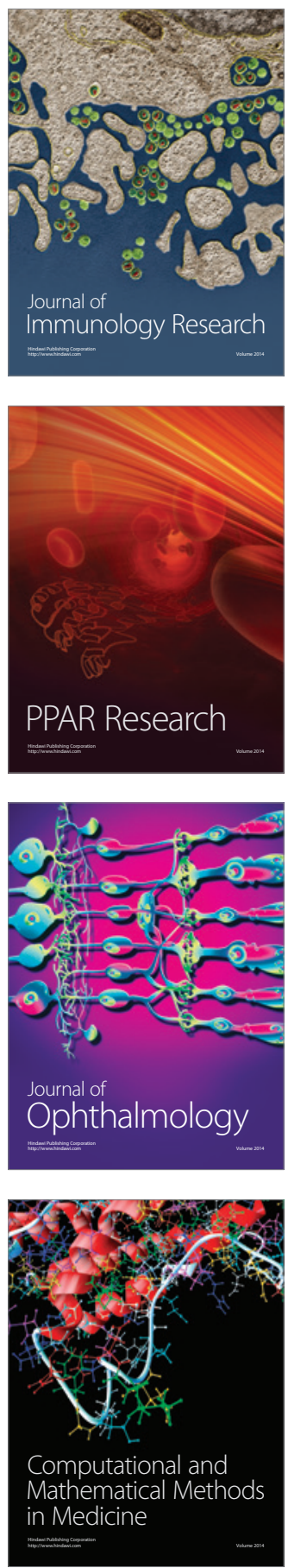

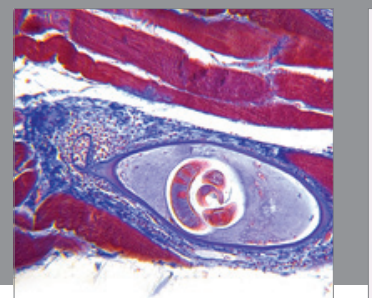

Gastroenterology

Research and Practice
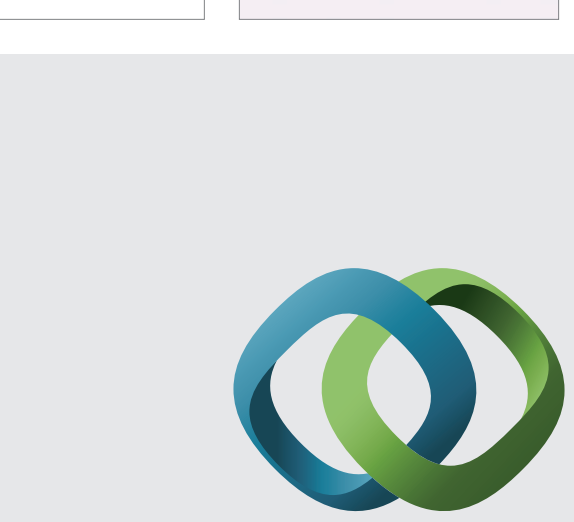

\section{Hindawi}

Submit your manuscripts at

http://www.hindawi.com
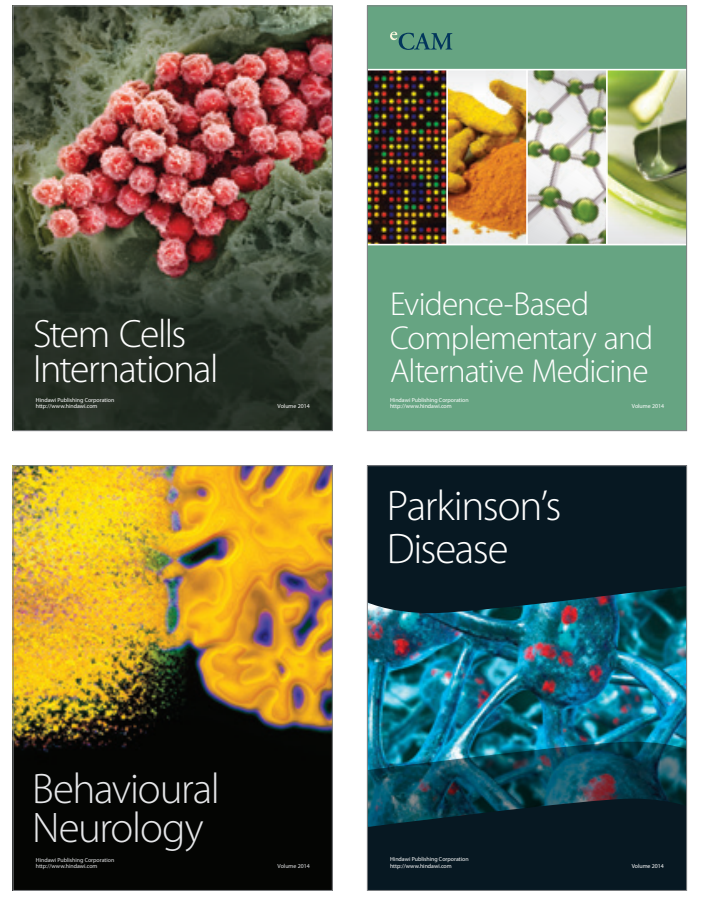
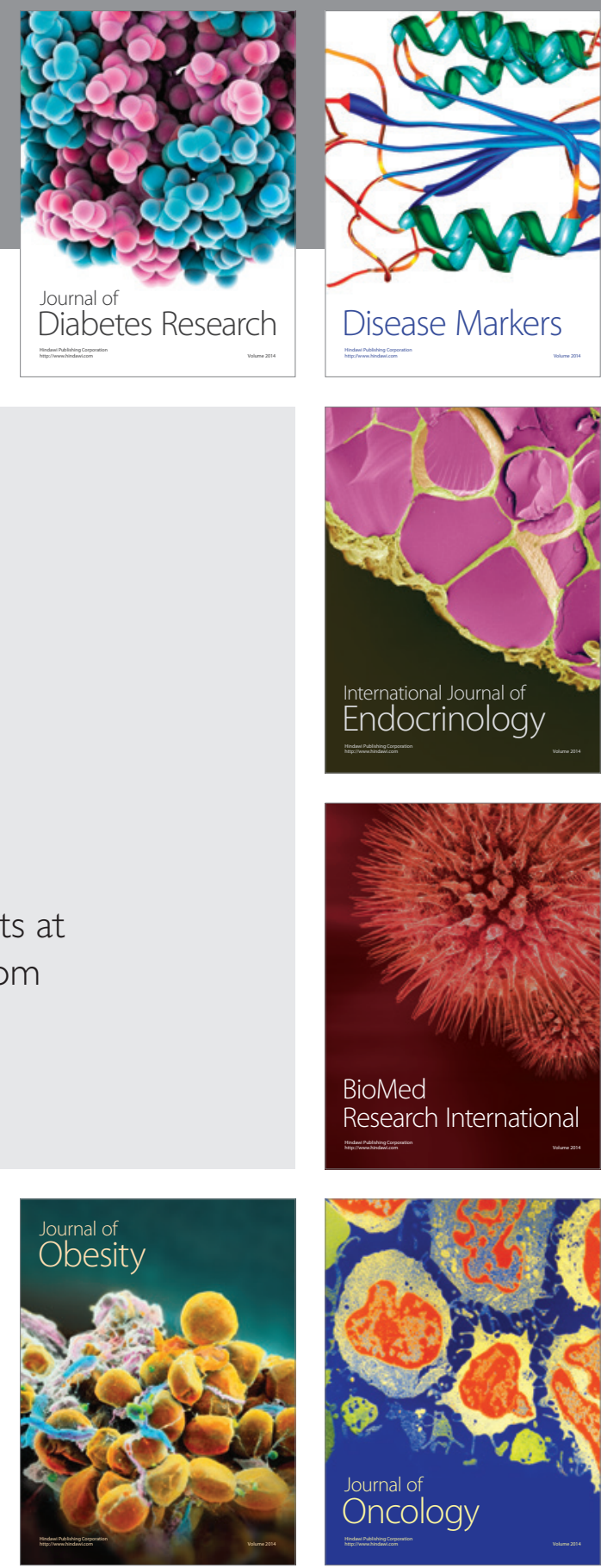

Disease Markers
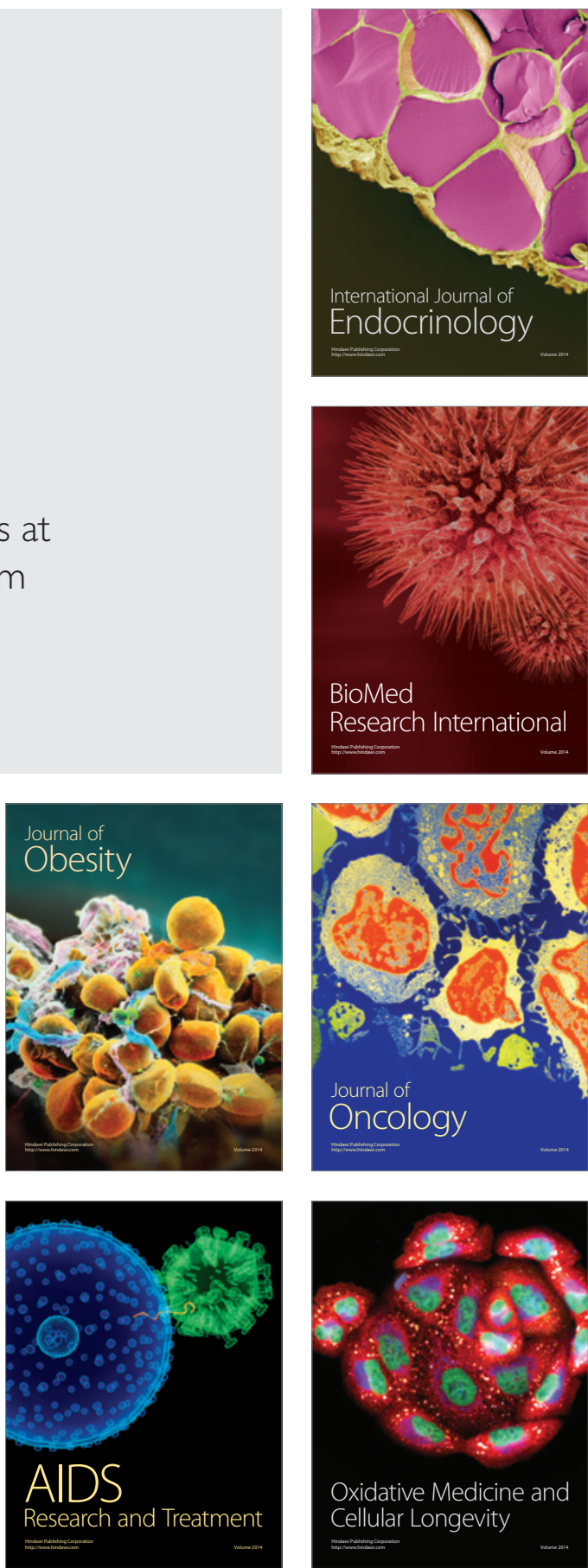